\title{
Recent dramatic evolution of the Journal of Gastroenterology (JG): a note from current Editorial Director and former Editor-in-Chief of JG
}

\author{
Mamoru Watanabe
}

Published online: 20 February 2015

(C) Springer Japan 2015

It is a great honor to pen few words for the recent dramatic evolution of the Journal of Gastroenterology (JG). JG is the official journal of the Japanese Society of Gastroenterology (JSGE). It was launched in 1966 as Gastroenterologia Japonica, and then the journal name was changed to Journal of Gastroenterology in 1994, and has completed 50 years of publication in 2015.

Only 10 years ago, no one could have imagined the current situation of JG. When I joined in the editorial team of JG in 2003, the journal had approximately 350 manuscript submissions per year. It was substantially a Japanese journal with $80 \%$ of the submitted manuscripts and $90 \%$ of the accepted manuscripts coming from Japanese gastroenterologists. Very few foreign researchers even know the name of the journal. I would like to let you know indispensable decisions and efforts of former Presidents of the JSGE, Editorial Directors, Editor-in-Chief, Deputy Editor-in-Chief, associate editors and editorial stuffs of JG to make JG put on the success process.

With Professor Tsutomu Chiba (Kyoto University), the previous Editor-in-Chief of JG, and Professor Yutaka Atomi (Kyorin University), the President of the JSGE at that time, we seriously discussed the short-term target and future prospects of the journal. We decided that the development of the journal would be the flagship for the internationalization of the JSGE. Professor Chiba kindly and surprisingly recommended me as the youngest Editorin-Chief in JG's history. I became an Editor-in-Chief in April of 2005 and finished a 6-year term in March of 2011. I had thought that our success depended on our team of

M. Watanabe $(\bowtie)$

Department of Gastroenterology and Hepatology, Tokyo

Medical Dental University, Bunkyo, Japan

e-mail: mamoru.gast@tmd.ac.jp associated editors. Professor Makoto Ohtsuki (Emeritus Professor University of Occupational and Environmental Health), Editorial Director at that time, asked the president of the JSGE to increase the number of associated editors, and change all members into young and promising investigators. With continuous enthusiasm to JG and encouragement to associate editors by the superb Deputy Editorin-Chief, Professor Kazuhiko Koike (Tokyo University), Professor Sumio Watanabe (Juntendo University), and associate editors had been working tremendously hard to establish JG to be an international journal. Most of the associate editors were either associate or assistant professors at that time, but now more than half of them became full professors of the Department of Gastroenterology and Hepatology in the many major universities in all over Japan. We made every effort to make the system based on peer reviews. We introduced an online system for JG and changed the cover of the journal in 2005. We also introduced the "online first" system in 2009 and the Open Choice service to make excellent manuscripts open access in 2011.

We pushed associate editors to make quick decisions and subsequently the average time from submission to first decision in 2013 was 20 days. In my term as Editor-inChief of JG, we established a strict initial evaluation process by the editor. Even the Editor-in-Chief and Deputy Editor-in-Chief had also made decision by themselves for 15-20 manuscripts per week. More than $70 \%$ of the submitted papers were immediately rejected. We decided to eliminate most retrospective clinical studies without establishing new concepts and some prospective clinical studies with only a small number of subjects. With these efforts, the acceptance rate of JG was significantly decreased from $25.8 \%$ in 2004 to $12.7 \%$ in 2013 . We made every effort to let many foreign leaders of gastroenterology 
and hepatology know JG in international meetings, and this resulted in a dramatic increase in the number of submissions from 361 in 2004 to 1,199 in 2013 (Fig. 1). This also resulted in a significant number of submissions from outside of Japan, and the submission rate from abroad was dramatically increased from $24.7 \%$ in 2004 to $64.8 \%$ in 2013 (Fig. 2). All of these efforts caused the impact factor of JG to remarkably increase from 1.209 in 2004 to 4.160 in 2011 (Fig. 3). This impact factor pushed JG to the journal with the highest impact factor among all journals in the medical area published in Japan in 2011. I have been asked by many foreign researchers and publishers about the success story of JG. We are sure that the success of JG could make the basis of internationalization of current JSGE. With the great efforts of former Editorial Director Hirohito Tsubouchi (Emeritus Professor of Kagoshima

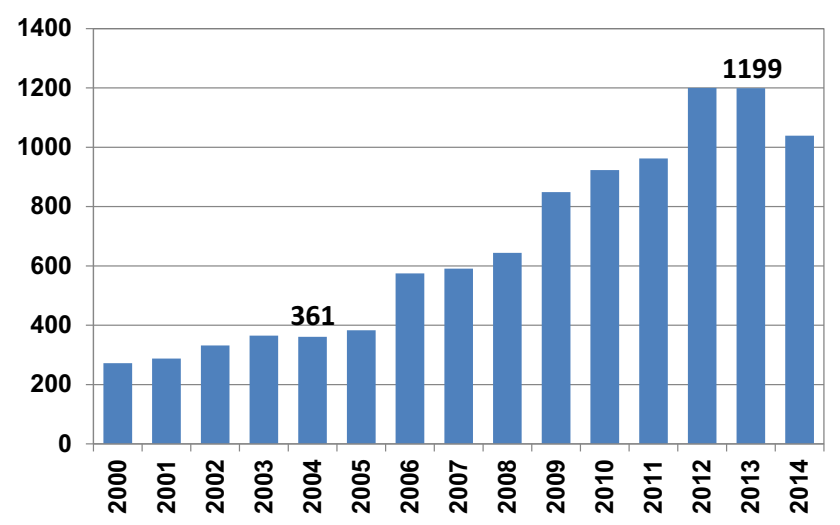

Fig. 1 The dramatic increase in the number of submissions over the past 10 years (Source: ScholarOne Manuscripts, as of 2014)

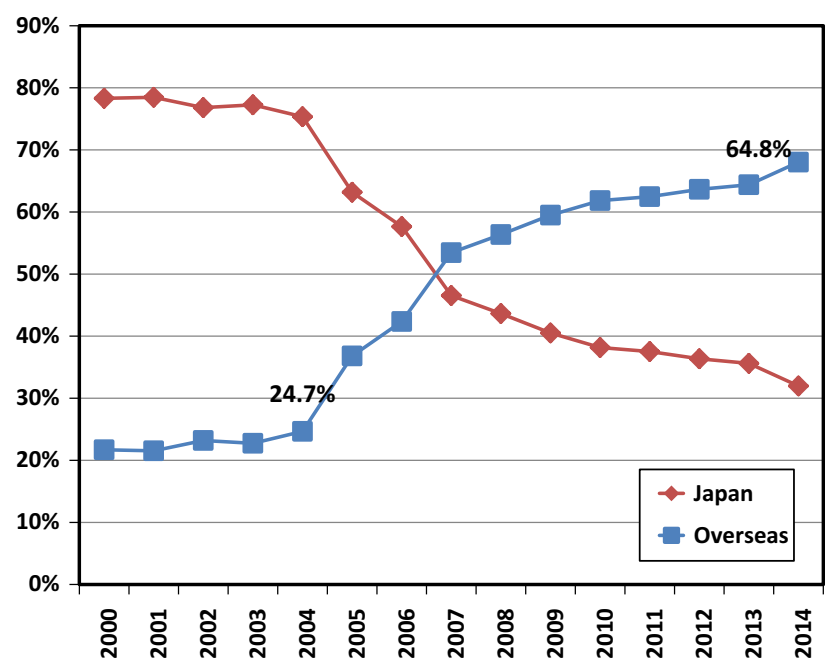

Fig. 2 The dramatic increase in overseas submissions. Currently, $70 \%$ of submissions are from overseas (Source: ScholarOne Manuscripts, as of 2014)

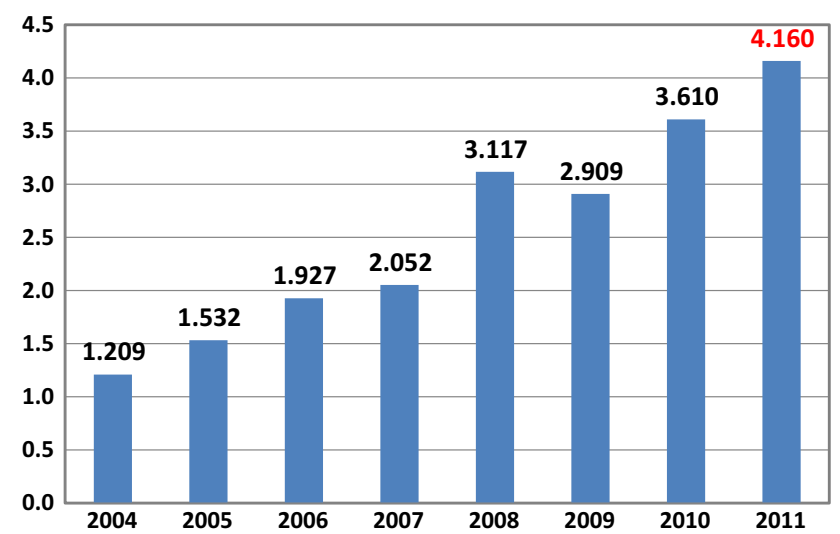

Fig. 3 The significant increase in the impact factor of JG (Source: Journal Citation Reports)

University) and former Editor-in-Chief Takeshi Azuma (Kobe University), JG has been going well.

The editorial team has been renewed in 2013. The current Editor-in-Chief Akira Andoh (Shiga University of Medical Science), Deputy Editor-in-Chief Naoya Sakamoto (Hokkaido University), and new associate editors returned to JG. I also came back to JG as an Editorial Director. I am delighted to announce that the 2013 impact factor of JG is 4.020 . Our ranking is now $15 / 75$ in gastroenterology journals, as compared to last year's ranking of 17/74. This is an excellent outcome and is a direct result of the dedication of the Editor-in-Chief, Deputy Editor-inChief, and associate editors to JG to uphold its standards of quality. The acceptance ratio will fall to around $8 \%$ in 2014. Thank you all for my editorial team continued commitment to the journal. JG is now available in 10,231 institutions worldwide via Springer's global network. Seventy percent of JG's subscriptions are currently managed under licenses globally. Since 2004, the initiatives including HINARI have given researchers in over 100 developing world countries free or low-cost access to over 13,000 peer-reviewed journals provided by 160 scientific, technical, and medical publishers. We are proud that JG is a part of this program. Full-text downloads for JG increased from 181,986 in 2011 to 203,853 in 2013, a $12 \%$ increase. Thank you all for editorial team continued commitment to the journal.

The current editorial team has developed the Journal of Gastroenterology into a more internationally recognized journal of scientific excellence in the fields of gastroenterology, hepatology, pancreatic-biliary and endoscopy, with a particular emphasis on clinical and basic research and continuing education. Balancing the needs of the region, the range of quality that is submitted across the world, and ensuring that the journal grows so that the quality further improves will be our challenge. The strategy of JG is to publish only significant articles and the most 
informative review articles. This should eventually ensure that Japan takes its rightful place among the top regions contributing to the knowledge and practice of gastroenterology.

We fully understand that we should make JG a more international journal. Various approaches have been doing by leadership of Professors Akira Andoh and Naoya Sakamoto. I am sure that JG would open new horizon in the JSGE and researches in gastroenterology from Japan.
Finally, I would like to stress that the success of JG would not have been achieved without the efforts of not only the current editorial team but also authors and readers from all countries. I like the old African proverb: "If you want to go fast, go alone. If you want to go far, GO TOGETHER". Let's GO TOGETHER for the expected future of JG as well as gastroenterology in the world. 